\title{
Electric drives for light e-scooters
}

\author{
P. Andrada, B. Blanqué, E. Martinez, M.Torrent, J.A. Sánchez, J.I. Perat \\ Electronically Commutated Drives Group (GAECE), Departament d'Enginyeria Elèctrica (DEE), \\ Escola Politècnica Superior d'Enginyeria de Vilanova i la Geltrú (EPSEVG). \\ Universitat Politècnica de Catalunya (UPC), BARCELONATECH \\ Avinguda Victor Balaguer 1, 08800 Vilanova i la Geltrú, Barcelona, Spain. \\ Phone number:+34 938967732; Fax number: \\ +34 938967700; pere.andrada@upc.edu
}

\begin{abstract}
In the next years is expected an important rise in sales of electrical scooters in the entire world but especially in China. In order to address this challenge the electric scooter industry has to be more competitive in the transportation market and therefore important improvements, in terms of energy density and costs, have to be done in the electric storage system and in the electric propulsion system. In this paper, an analytical and experimental comparison of two different drives for electric scooters is carried out. Both are permanent magnet synchronous outer rotor motor drives but one placed inside the rear wheel and the other connected to the wheel trough a mechanical transmission.
\end{abstract}

\section{Key words}

Electric motors, electric drives, electric scooters.

\section{Introduction}

Scooters are very popular for personal transportation in urban areas, based on their low cost of purchase and operation and on benefits that include driveability with heavy traffic and parking in a limited space. Nowadays, it begins to be a demand for electric scooters because in addition to the advantages of conventional scooters they are environmental friendly (no $\mathrm{CO}_{2}$ and no harmful emissions from the tailpipe, little noisy) and save energy. According to a Pike Research study, the number of electric scooters in use is to increase from 12 million to 103 million by 2018 [1]. Most of these vehicles will be used in China (approximately 91 million) due to rising urbanization and thus the increase of population density, the rise in income levels, and the government policies that are all fueling the demand for lightweight, highly mobile electric scooters. In Europe although there is a willingness of people towards e-mobility there are barriers for the market introduction of electric scooters. These barriers are high purchase price, reduced autonomy, lack of charging facilities and few governmental measures supporting the industry and promoting regulations to encourage the use of electrical scooters. In addition many models are imported from Asia and they have poor quality according to the European standards and many others are built using imported assembly parts for distributors and dealers attracted for an emerging business but without know-how and experience. The scooter industry has to be more competitive in the transportation market and important improvements, in terms of energy density and costs, have to be done in the electric storage system and in the electric propulsion system. Battery technology has made great progress extending the per change range near $160 \mathrm{~km}$ and making lithium batteries affordable for electrical scooters. In the electric propulsion system it is necessary to develop new low cost more efficient and reliable drives with high torque to weight ratio for a smaller space. This paper is devoted to the case of the electrical drive for the light escooters that is comparable with a low performance 50 $\mathrm{cm}^{3}$ gasoline scooters. The paper is organized as follows: First a brief description of the complete electrical system and an exposition of their design considerations and requirements are presented, in second place an historical review of the electrical drives used for electrical scooter is exposed, then an analytical and experimental comparison of two different drives is performed, both permanent magnet synchronous outer rotor motor drives but one placed inside the rear wheel and the other connected to the wheel trough a mechanical transmission. Finally conclusions from this research are drawn.

\section{Electric system}

The electric storage and propulsion scheme of an electric scooter is shown in Figure 1. Nowadays the electric storage pack is usually formed by Lithium batteries and a battery management system. The propulsion system includes an electric motor (M) fed through an electronic power converter in which the switching sequence of the solid state switches, usually Power Mosfets, are controlled by an electronic control unit (ECU) by the information obtained from the position/speed transducer, the current sensor and the acceleration command. 


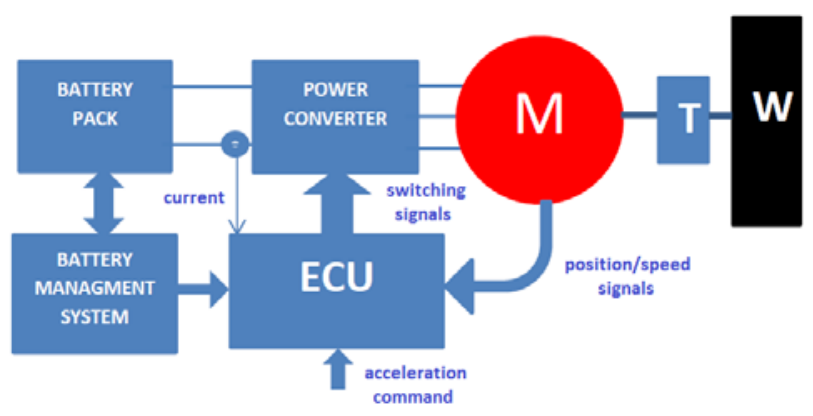

Fig.1 Electric Storage and Propulsion scheme of an electric scooter

The torque delivered by the motor is transmitted to the wheel (W) through a mechanical transmission (T).

\section{Design considerations}

The dynamic equation of motion of a vehicle is given by [2]:

$\mathrm{T}=\left(\mu_{\mathrm{r}} \cos \beta \pm \sin \beta\right) \operatorname{mgR}+\frac{1}{2} \rho \mathrm{C}_{\mathrm{D}} \mathrm{A}\left(\mathrm{v} \pm \mathrm{v}_{\mathrm{o}}\right)^{2} \mathrm{R}+$ $\mathrm{k}_{\mathrm{m}} \mathrm{m} \frac{\mathrm{dv}}{\mathrm{dt}} \mathrm{R}$

(1)

Where:

$T$, is the torque at the wheel $(\mathrm{Nm})$

$m$, is the gross (total) mass $(\mathrm{kg})$

$\beta$, is the grade angle from horizon

$R$, is the radius of the tire (m)

$\mu_{r}$, is the rolling resistance coefficient

$g$, is the acceleration of gravity $\left(\mathrm{m} / \mathrm{s}^{2}\right)$

$\rho$, is the air density $\left(\mathrm{kg} / \mathrm{m}^{3}\right)$

$A$, is the frontal area $\left(\mathrm{m}^{2}\right)$

$v$, is the speed of the vehicle $(\mathrm{m} / \mathrm{s})$

$v_{0}$. is the head wind speed $(\mathrm{m} / \mathrm{s})$

$C_{D}$, is the aerodynamic drag coefficient

$k_{m}$, is the inertia coefficient

The grade angle and gradeability in percentage (p) are related by:

$\beta=\operatorname{arctg} \frac{\mathrm{p}}{100}$

Motor speed is given by:

$\omega_{\mathrm{m}}=\frac{\mathrm{v}}{\mathrm{R}} \mathrm{i}$

And the torque of the motor is calculated as:

$\mathrm{T}_{\mathrm{m}}=\frac{\mathrm{T}}{\mathrm{i} \eta}$

Where:

$i$, is the gear ratio

$\eta$, efficiency of the transmission

The scooter design parameters are given in table I. In Figure 2 are depicted the required wheel torque versus speed alongside isolines of equal power calculated using equations (1-3), showing clearly the influence of gradeability. The main requirements for the light electric scooter considered are collected in Table II. These requirements are modest as befits to an urban light scooter with low climbing capability and limited maximum speed.

Table I. Main parameters of the proposed light e-scooter

\begin{tabular}{|c|c|}
\hline Parameters & Values \\
\hline $\mathrm{m}(\mathrm{kg})$ & 175 \\
\hline$\mu_{\mathrm{r}}$ & 0.007 \\
\hline$\rho\left(\mathrm{kg} / \mathrm{m}^{3}\right)$ & 1.23 \\
\hline $\mathrm{C}_{\mathrm{D}}$ & 0.7 \\
\hline $\mathrm{R}(\mathrm{m})$ & 0.2752 \\
& $90 / 8016$, \\
\hline $\mathrm{A}\left(\mathrm{m}^{2}\right)$ & 0.6 \\
\hline $\mathrm{k}_{\mathrm{m}}$ & 1.05 \\
\hline
\end{tabular}

Table II. Main requirements for the proposed light e-scooter.

\begin{tabular}{|c|c|}
\hline Requirements & values \\
\hline Speed (max) & $45 \mathrm{~km} / \mathrm{h}$ \\
\hline Voltage & $48 \mathrm{~V}$ \\
\hline Torque at $45 \mathrm{~km} / \mathrm{h}$ & $35 \mathrm{Nm}$ \\
\hline $\begin{array}{c}\text { Gradeability at } 20 \mathrm{~km} / \mathrm{h} \text { and } \\
\text { corresponding torque }\end{array}$ & $12 \%$ \\
& $61.75 \mathrm{Nm}$ \\
\hline
\end{tabular}

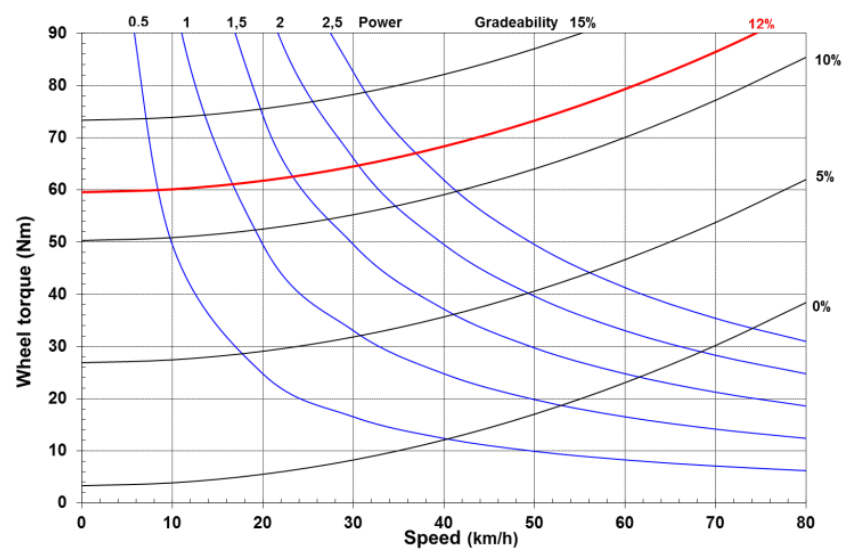

Fig.2 Required wheel torque vs speed and gradient. 


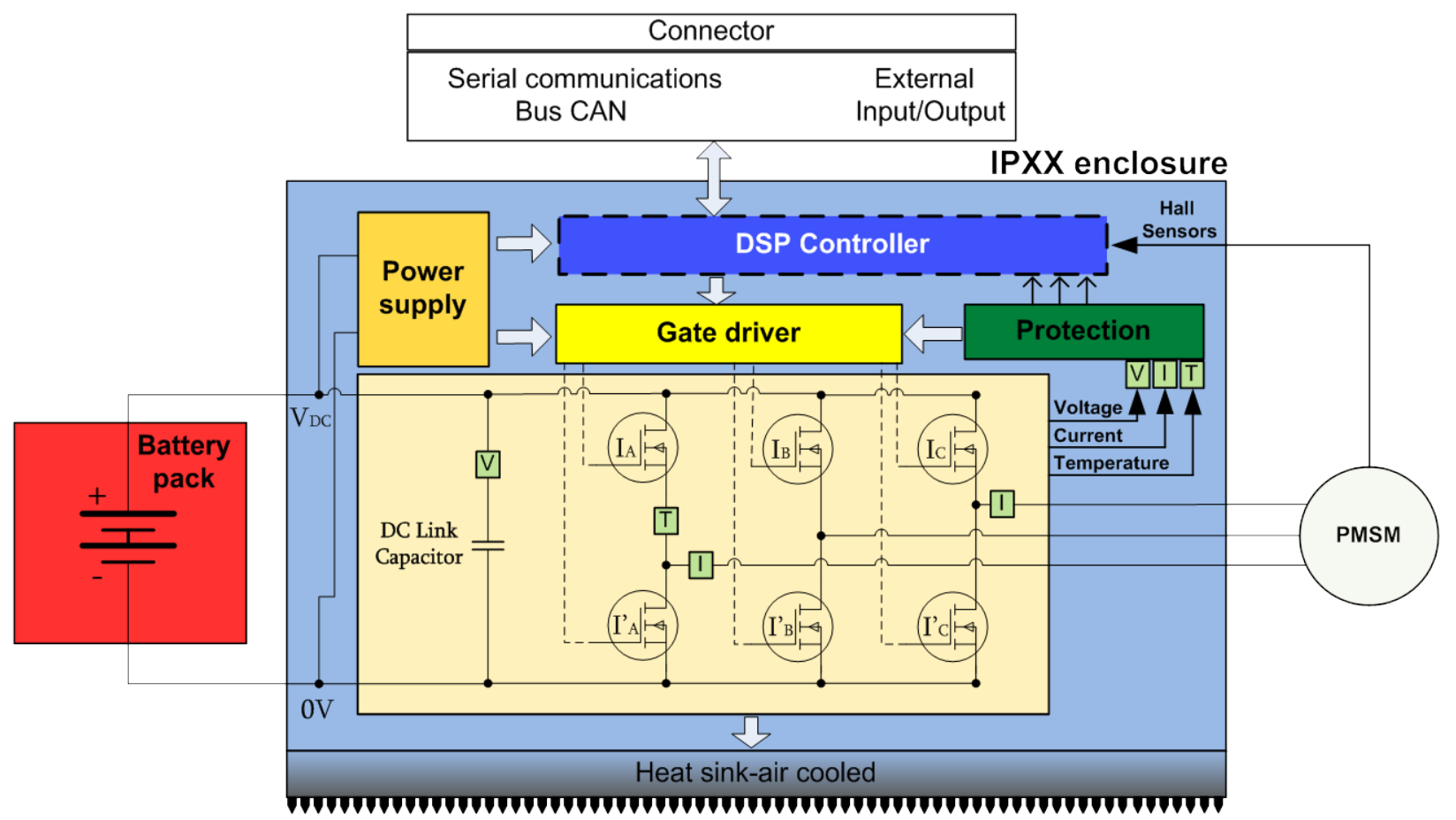

Fig. 3 Power converter and ECU architecture.

In regard to the position where the motor is mounted two options will be considered: motor placed in the middle of the scooter frame (mid-drive motor) which requires a mechanical transmission between the motor and the wheel and motor placed inside the rear wheel (in-wheel motor or hub motor). The main advantages and drawbacks of both dispositions are listed in Table III [3].

Tabla III. Advantages and drawbacks of motors according to their placement in scooters

\begin{tabular}{|c|c|}
\hline \multicolumn{2}{|c|}{ Advantages } \\
\hline $\begin{array}{c}\text { Mid-drive motors } \\
\text { In-wheel motors } \\
\text { scooters }\end{array}$ & There is not transmission \\
\hline $\begin{array}{c}\text { Lightweight } \\
\text { High efficiency }\end{array}$ \\
\hline \multicolumn{2}{|c|}{ Drawbacks } \\
\hline Mid-drive motor & In-wheel motor \\
\hline Transmission is required & Are unsprung mass in the wheel \\
\hline $\begin{array}{c}\text { Need space in the frame of } \\
\text { the scooter }\end{array}$ & $\begin{array}{c}\text { Break the balance of the mass of } \\
\text { the scooter towards the rear } \\
\text { wheel }\end{array}$ \\
\hline & Heavyweight \\
\hline & Low efficiency \\
\hline
\end{tabular}

\section{Electric drives for e-scooters}

In the last decades different electric drives have been used for propulsion of electric scooters. In 1996 Peugeot launched the "Scoot'elec" that was propelled by a DC separately excited motor. This same year Charichi et al. proposed a slotless axial-flux permanent motor [4] as in- wheel motor for direct traction. Bianchi et al. made a detailed study of interior permanent-magnet synchronous motor and showed its suitability for electrical scooters [5]. In the last years many authors have made contributions to the development of outer rotor brushless DC motor for light electric vehicles [6-8]. The switched reluctance motor was focus of interest due to its application in the LECTRA EMB VR24 [9] in the last years of the XX century and recently it has become again an alternative in its segmented outer rotor version, as a traction motor for electrical scooters [10]. Right now there is a tendency to use outer permanent magnet synchronous motors placed inside the wheel [11].

The power converter and the electronically control unit are usually integrated and have an architecture as shown in Figure 3. This can be done specifically for each motor but can also be used commercial equipment. These equipment were originally designed to control AC motors fed from batteries for traction applications (on road and off road) and other applications, they integrate in a small box the power converter and the ECU hardware and meet the demanding specifications of vibrations and temperature required by the electronic devices used in electrical traction. In some cases the software is included and makes possible to adapt it to the specific characteristics of the scooter [12]. In some other cases the software is not included and therefore should be designed purposefully [13]. 


\section{Comparison of two permanent magnet synchronous motors for light e-scooters}

In order to select the most suitable drive for a light electric scooter a comparison of two permanent magnet synchronous motor (PMSM) drives has been performed. One of the drives, drive direct traction without a transmission and therefore the motor has outer rotor, inwheel motor. In the other drive, a mid-term drive, there is a mechanical transmission between the axis of the motor and the wheel but also has outer rotor. Both motors have three phases and a nominal voltage of $48 \mathrm{~V}$, use neodymium magnets and concentrated fractional slot windings. The PMSM with mechanical transmission has 10 poles and 24 slots, and the power converter and the ECU are integrated on the motor while in the in-wheel PMSM drive the motor, has 46 poles and 51 slots, and the power converter and the ECU are placed apart. The total mass of the mid-term drive with mechanical transmission is only $3.4 \mathrm{~kg}$ while the in-wheel PMSM drive has a total mass of $10.43 \mathrm{~kg}(1.13 \mathrm{~kg}$ of the power converter and ECU). The in-wheel PMSM can provide a torque of 35 $\mathrm{Nm}$ at $500 \mathrm{rpm}$ and the mid-term motor with mechanical transmission is capable to give up to $15 \mathrm{Nm}$, but can ensure $8 \mathrm{Nm}$ at $2000 \mathrm{rpm}$. In order to match the mid-term motor characteristics to the scooter requirements a gear ratio of at least 4:1 is required. Torque-speed characteristics of the drive and the global efficiency (including power converter) vs torque of the in-wheel motor drive were measured using the experimental setup show in figure 4 . The experimental torque-speed characteristics are depicted in figure 5 , lines with markers, in which the wheel torque-speed envelope of the considered scooter, according to table II, is represented in order to facilitate the interpretation of its suitability to the application.

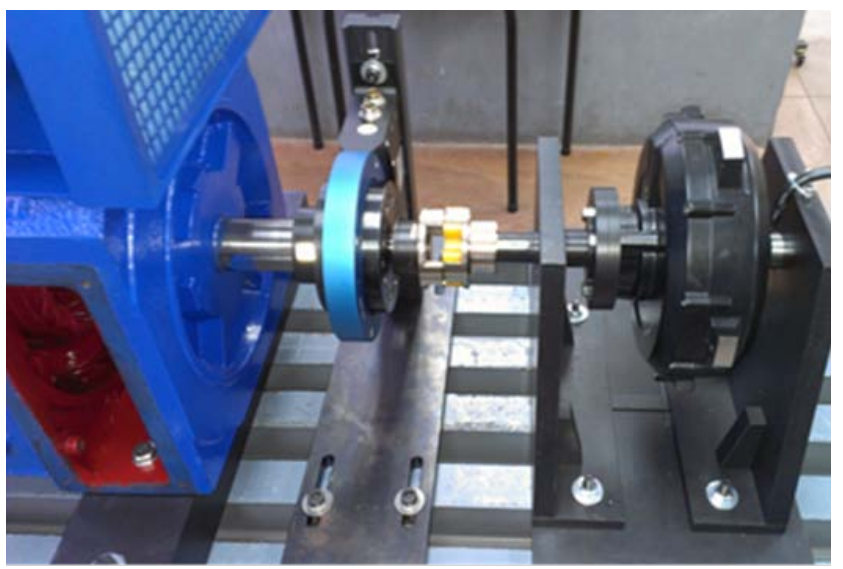

Fig. 4 Experimental set up

The torque-speed characteristics of the mid-term drive were obtained directly from the manufacturer catalogue [14] adapted to the scooter requirements by means of equation (4) and they are shown in figure 6 together the wheel torque-speed envelope of the considered scooter, according to table II.

The efficiency of both drives against torque is shown in figure 7 , blue line for the mid-term drive and red line for the in-wheel motor drive. It is important to point out that the efficiency is the global efficiency, considering motor and power converter efficiency. In the case of the midterm drive information, about of global efficiency was also obtained also from manufacturer catalogue the efficiencies represented in figure 7 includes the efficiency of the transmission that was estimated in $97 \%$.

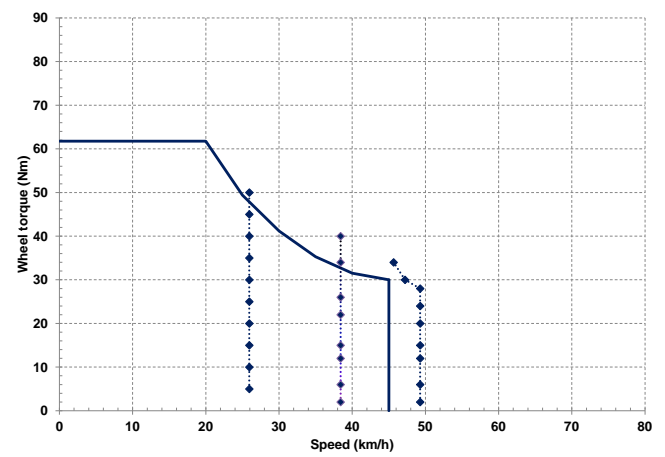

Fig. 5 Experimental torque-speed characteristics (lines with markers) and required torque-speed envelope (thick line) for the in-wheel motor drive.

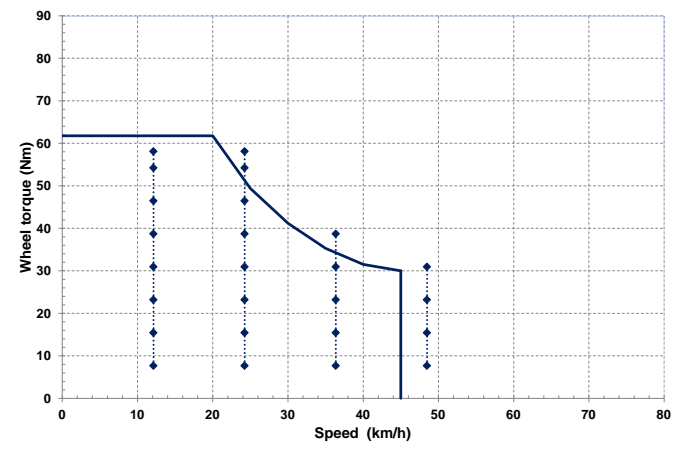

Fig. 6 Torque-speed characteristics (lines with markers) and required torque-speed envelope (thick line) for the mid-term motor drive.

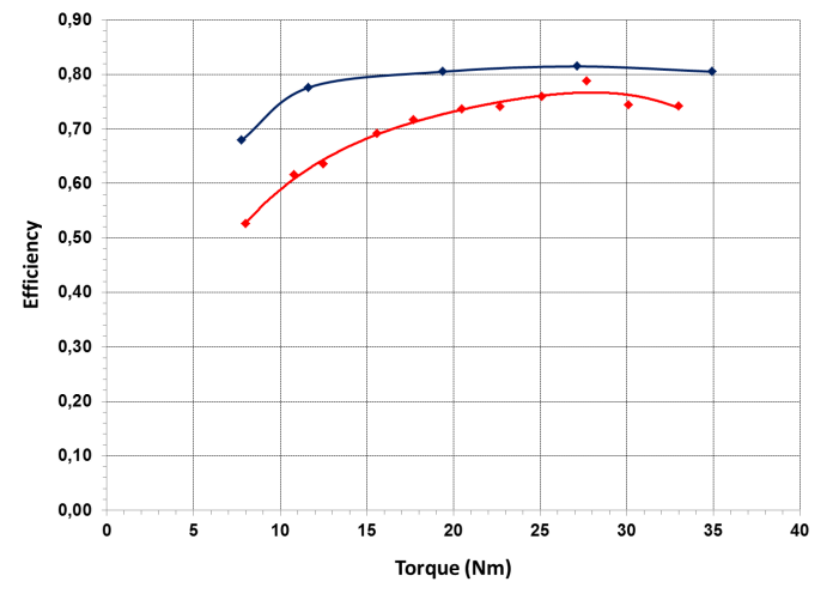

Fig. 7. Efficiency vs. torque, red line in-wheel motor drive, blue line mid- term drive. 


\section{Conclusion}

In this paper, an analytical and experimental comparison of two different drives for the propulsion of light escooters is performed. Both are permanent magnet synchronous outer rotor motor drives but one placed inside the rear wheel and the other connected to the wheel trough a mechanical transmission. From this analysis can be conclude that the efficiency and mass is clearly favourable to the mid-term drive but this drive requires a mechanical transmission with a gear ratio of $4: 1$ in order to obtain the same torque capability than the in-wheel motor, although in addition provides the same advantages of maneuverability of a conventional scooter equipped with internal combustion engine. Anyway both alternatives could be a good option depending on the e-scooter design assumptions.

\section{Acknowledgement}

Authors would like to thank DOGA S.A. for its assistance and financial support

\section{References}

[1] PikeResearch. "Electric two-wheel vehicles: Electric bicycles, mopeds, scooters and motorcycles market analysis and forecast”. www.pikeresearch.com

[2] C.C. Chan, K.T. Chau. "Modern Electric Vehicle Technology”. Oxford Science Publications 2001.

[3] D.J.van Schalkwyk and M.J. Kamper. "Effect of hub motor mass on stability and comfort of electric vehicles". Proceedings of the IEEE Vehicle Power and Propulsion Conference (VPPC), September 2006, pp. 1-6.

[4] F. Caricchi, B. Crescimbini, O. Honorati, E. Santini. "Compact wheel direct drive for EVs". IEEE Industry Applications Magazine. November/December 1996, pp. 2532.
[5] N. Bianchi, S. Bolognani, M. Zigliotto. "Highperformance PM synchronous motor drive for an electrical scooter”. IEEE Transactions on Industry Applications, Vol 37, No 5, September/October 2001, pp. 1348-1355.

[6] B. Song, K. Chang, J. Choi. "Design of an outer-rotor-type permanent motor for electric scooter propulsion systems". International Power Electronics Conference 2010, pp. 2736-27.

[7] N. Ravi, S. Ekram, D.Mahajan. "Design and development of a in-wheel brushless D.C. motor drive for and electric scooter”. Proccedings of International Conference on Power Electronics Drives and Energy Systems (PEDES). December 2006.

[8] M. Bertoluzzo, G. Buja. "Development of electric propulsion systems for light electric vehicles". IEEE Transactions on Industrial Informatics, Vol 7, No 3, August 2011, pp. 428-435.

[9] LECTRA EMB VR24. www.electricmotorbike.org

[10] V. Vandana, B.G. Fernandes, "Optimal sizing of motorbatteries for in-wheel electric vehicles”. IECON 2010, pp. 2510-2515.

[11] W. Gruber, W. Bäck, W.Amrheim. "Design and implementation of a wheel hub motor for an electric scooter". Proceedings of the IEEE Vehicle Power and Propulsion Conference (VPPC), 2011, pp.1-6

[12] SEVCOM GEN 4 Applications Reference Manual.

[13] R. Mühlemann, P. Newman. SKAI Technology-Compact Vehicule Power Electronics Systems. SEMIKRON, pp. 19.

[14] Compact Power Motors. Power Pack, CPM 90-45-3000-L$48 \mathrm{~V}$. www.cpmmotor.eu 